OPEN ACCESS

\title{
Two Paths of Korea's Clustering: Centralized De-concentration and Regionalized Concentration
}

\author{
Shi-Chul Lee \\ The School of Public Administration, Kyungpook National University, Republic of Korea
}

Abstract: This paper presents, from a broad perspective, the manner in which various types of clusters and options for regional development have evolved in Korea over the past decade, with particular emphasis on who have taken initiative in establishing the clusters. Characterized by not only progress but also setbacks, two distinctive patterns have emerged: centralized de-concentration and regionalized concentration. Both the Korean government and numerous localities have continuously extended efforts to create different clusters, technology parks, special districts, etc. In many cases, local or regional governments have competed intensely for clusters to be located in their jurisdictions; in particular, concerted efforts to convince national governments to set up special districts have been witnessed. On the other hand, major localities have made their own efforts to generate large- and small-scale clustering projects. It remains to be seen how different outcomes or effectiveness these two approaches will make in the future.

Following the review of relevant literature and practices, I examine the well-known national campaign and projects in the previous administration in Korea in the context of 'de-concentration' of economic values and resources. Thereafter, other cases initiated mostly by local governments are discussed; some of these clustering efforts and regional projects have fared well thus far, but some haven't. In the case of Daegu, the progress of some critical projects, such as the Daegu Technopolis and a Free Economic Zone, is elaborated.

Keyword: Cluster, De-concentration, Technopolis, Regional development, Daegu, Korea

\section{CLUSTERS IN LITERATURE AND IN PRACTICE}

Although known by various names in reality (e.g. clusters, special districts, techno-parks, technopolis), specific areas with strong economic, technical, or cultural assets in different settings have been created around the world. In Korean soil, the intent has been not only to spur national economic growth but also to help localities compete with other areas in the global market and within Korea. Whether clusters have grown spontaneously or been planned intentionally by the public sector is also of significance.

*Correspondence to : Shi-Chul Lee

Professor of the School of Public Administration at Kyungpook National University, Dean of the KNU Graduate School of Public Administration, Republic of Korea

E-mail : shichul@knu.ac.kr

World Technopolis Review

Copyright $\odot$ World Technopolis Association

CC This is an open-access article distributed under the terms of the Creative Commons Attribution Non-Commercial License(http://creativecommons.org/icenses/by-nc/3.0) which permits unrestricted noncommercial use, distribution, and reproduction in any medium, provided the original work is properly cited
A cluster can be defined in various ways; when labeled in narrow terms, it refers to a "geographical agglomeration of firms with similar or highly complementary capabilities" (Richardson 1972). A further extended definition is a spatial "concentration of interconnected companies, specialized suppliers, service providers, firms in related industries, associated institutions (for example, universities, standards agencies, and trade associations) in particular fields that compete but also co-operate" (Porter 1998).

The Diamond Model given by Porter (2000), which explains clusters in the context of regional competitiveness, has been reiterated and patterned with great enthusiasm in diverse literature and in practice. In a similar vein, this paper will discuss "clusters" as a most critical means for local or regional development; they will encompass a broad spectrum embracing technology parks, industrial districts, special districts, and other geographical agglomeration that have been systematically planned. 
In fact, there is no shortage in literature with regard to the manner in which clusters or clustering contribute to regional economy. Since Porter (1990; 1998; 2000) discussed the competitiveness and productivity of national economy, clustering along with innovation system has been considered as an important approach for regional competitiveness (Maskelland Lorenzen 2006; Park 2004; Porter 1998). It is also maintained that the clustering of complementary firms improves regional competitiveness and enables the creation of jobs as well (OECD 2002).

Yet it is not quite clear that any nature of clustering invariably brings innovation, competitiveness, and eventually economic prosperity at the local or regional level, although there have been some world-renown successful examples such as Silicon Valley and Oulu. Also, clustering embraces a number of other elements and dimensions; it usually refers to research \& development combined with relevant industries while sometimes featuring value chains composing of firms, businesses and even government activities. Among others, two critical factors in any cases would certainly be geographical agglomeration and interdependence.

Certain differences ought to be identified when comparing American cases and most Asian practices. Such 'old economy' factors as entrepreneurial talent, skilled labor, direct university-industry interaction do not appear as clear or indispensable in Japan and Korea as in Silicon Valley or Route 128(Feldman and Francis 2006). Centralized planning by national/regional government later associated with firms and colleges have been prevailing in Asian examples: Tsukuba, Daedeok, Hsinchu, etc. That has also been the case with many European examples, as indicated in Finland, Germany and Sweden.

The issue of clusters is rather familiar in Korea as well, both in academia and practice. The Korean government has continuously adopted initiatives in creating and extending a number of different clusters or technology parks around the nation. A unique justification for cluster development in this nation has been spatial equity, particularly since late 1990 s. While Seoul attempting to seek nationwide 'balanced development,' local or regional governments have competed intensely to attract clusters mainly for economic purpose, which itself usually carries serious political implication in each jurisdiction. Then, they have also made a great deal of efforts to create their own clusters within.

The previous decade has witnessed the concerted efforts of the local or regional governments - in terms of mobilizing politics, local press and government, and business resources for convincing the national government and, occasionally the National Assembly, to attract clusters or special districts, together with accompanying resources, into their own areas.

Does the creation of clusters actually nurture entrepreneurship or ignite local economic development? What would be the best methods for creating or managing clusters? This paper does not intend directly to answer these questions, to supply quantifiable evidence for a theory, or to provide policy suggestions readily available. Instead, I will outline what happened in Korea with respect to the development pattern of clusters and a few easily observed frames.

Following this section, the manners in which clusters or special districts have evolved and settled around the nation will be examined. With regard to some regional case, certain selected individual projects are highlighted. A few large-scale projects that are underway or waiting for launch include a Free Economic Zone (FEZ) and the Daegu Technopolis.

\section{TWO PATHS IN CLUSTER DEVELOPMENT IN KOREA}

As is the case of a city, it is of considerable importance whether clusters have grown spontaneously or been planned intentionally by the public sector. Korea has been well known for its rapid economic growth since the late 1960s and technical innovation in the past decades; scholars attribute this, at least partially, to centralized planning unbalanced development policies employed by the national government until the early 1990s. Most industrial development based on domestic and foreign investment was intended to take place in the southeast part of the nation. A rather unique example is Daedeok Science Town initiated by the national government in the early 1970s and constructed in Daejeon, an inland regional city.

No matter what the name or the brand was, there were rarely a period in Korea since 1970s that the government has not paid enough attention to development of highly concentrated agglomeration of research institutes or industrial businesses in certain areas. The previous Roh administration (Feb. 2003 - Feb. 2008) and the current Lee Administration are not exceptions, either. How then would cluster development in the past decade fit in the context of cluster growth or the national development strategy when taken in its entirety? 
Among others, one can examine the pattern of clustering from the viewpoints of initiating role. After all, it is not easy to find clusters in Korea that have spontaneously grown on their own, that is, purely through market mechanism. Yet there appear to be some variation among clusters, for many of which national government played a key role to take initiative in establishing the concepts, identifying the project sites, and physically making it happen, while a few others were mainly led by impatient regional governments. In this vein, two patterns of cluster development are presented as shown in (Table 1): centralized de-concentration and regionalized concentration.

Perhaps one of the clearest examples of centralized deconcentration campaign would be the national 'balanced development' policy of the former President Roh's Participatory Government during its five-year reign. It is considered, to a great extent, as unprecedented efforts toward spatial equity. This is important partially because more conservative Lee administration since 2008 has made it clear to detour from the course adopted by the progressive Roh administration and to usher the nation into a new territory in national spatial policy.

The other type of clustering has been kicked off occasionally by the regional governments, that is, metropolitan governments in Korea such as Daegu and Incheon. For instance, Daegu Technopolis project was initiated almost solely by Daegu Metropolitan City, as discussed later on. Other numerous nationwide small-scale special districts can also be described in a similar vein. With limited administrative support and financial assistance from Seoul, these clusters have had to go through both grass-root expectations and realworld challenges.

While national government sought balanced development with emphasis on equity, survival was the key issue for many localities that had suffered from declining population and economic power. For those major national projects like Innocities and Enterprise Cities, which will be discussed later with details, full legislative and financial support were provided; that was not exactly the case with regionally-initiated projects like Daegu Technopolis. The national government-initiated projects were highly centralized in terms of legal and financial basis, while pursuing intentionally de-concentrate socioeconomic values throughout the nation. As shown in [Table 1], regional efforts were not always welcomed warmly by Seoul despite region-wide efforts and cooperation - hence, limited momentum and financial resources.
Table 1. Two paths of Korea's cluster development during 2000s

\begin{tabular}{l|l|l}
\hline & \multicolumn{1}{|c|}{$\begin{array}{c}\text { Centralized } \\
\text { de-concentration }\end{array}$} & Regionalized concentration \\
\hline explicit goals & $\begin{array}{l}\text { national balanced } \\
\text { development }\end{array}$ & $\begin{array}{l}\text { local survival, } \\
\text { endogenous growth }\end{array}$ \\
\hline $\begin{array}{l}\text { major initiating } \\
\text { actors }\end{array}$ & national government & regional / local government \\
\hline primary values & equity & efficiency \\
\hline $\begin{array}{l}\text { institutional } \\
\text { support }\end{array}$ & $\begin{array}{l}\text { ・ legislative support } \\
\text { port }\end{array}$ & $\begin{array}{l}\text { ・ regional governments' } \\
\text { support } \\
\text { region-wide cooperation } \\
\text { - grants-in-aid from national } \\
\text { government }\end{array}$ \\
\hline Cases & $\begin{array}{l}\text { Enterprise cities } \\
\text { - Inno-cities }\end{array}$ & $\begin{array}{l}\text { - Daegu Technopolis } \\
\text { - Daegu Gyeongbuk Free } \\
\text { Economy Zone } \\
\text { region wide large-scale } \\
\text { projects }\end{array}$ \\
\hline
\end{tabular}

\section{CLUSTERING IN THE DE-CONCENTRATION CONTEXT}

Clustering, in rough and broad terms, can be defined as "locating related activities close together" or, in urban planning terms, refer to land-use patterns in which related activities are located in close proximity (Online TDM Encyclopedia 2007). In what manner have clustering processes occurred in the national setting in Korea?

\section{1 "Big picture" de-concentration: rain checks or reality check?}

“... Decentralization of power to the provinces and balanced national development has become tasks that cannot be put off any longer. The central and the provincial parts of the country should be developed in a harmonious and balanced manner. The provinces should design their own future autonomously.... I will press ahead with the task with unusual resolve..." (President Roh Moo-hyun at the inaugural ceremony on Feb. 25, 2003).

Those were words of the past; expressions such as decentralization or balanced development were not mentioned even once in the inaugural address by President Lee on February 25, 2008. Yet, it is still important to overview how the distribution process of national values and resources was established and might change in the future.

Even before the inauguration in 2003, the Participatory Government had clarified a shift in the entire paradigm of 
national development; state priorities were to be ascribed to provincial or less developed areas outside the Capital Region and a mixture of economic resources were redistributed along the line. The Special Law governing Balanced National Development, enacted in 2003, was just one of many institutional measures undertaken for "balanced development."

A special account maintained since 2004 was a major financial source for the approach of the Roh administration. The unique fund exclusively reserved for balanced development was launched with an amount of $\$ 5.5$ billion it was scheduled to increase $8.5 \%$ every year and has been allocated for the purpose of balancing less developed regions (Lee 2007).

The construction of the New Administrative Capital in Chungnam Province, one of the initial grandiose schemes, was proposed during the presidential campaign of 2002. It primarily suggested that 85 ministries and government agencies, along with thousands of public officials and their families, were to be relocated to the newly constructed administrative capital by the year 2030. However, the daring and symbolic project did not survive, largely due to political barriers and the ruling of the Constitutional Court in October 2004. The alternative to the unsuccessful attempt was the "Multifunctional Administrative City" (MAC), which would function as the second capital of the nation if completed. The Presidential Office, National Assembly, and Supreme Court would remain in Seoul (Lee 2007 for details).

The term of the Roh administration officially ended on February 2008; it is difficult to wholeheartedly celebrate when it comes to the reality of the aforementioned spatial de-concentration efforts (Kim 2005; Lee 2005) or cluster development, although a few cases deserve mention and ought to be appreciated.

The New Administrative Capital project was significantly downgraded since 2005 to building a "Multifunctional Administrative City" in the same area, approximately one and a half hours south of Seoul. The newly-built city, Sejong, to be governed by a regional-level government based on a 2010 law, is expected to be home to 500,000 residents by 2050 ; the ministries will relocate to the new city from 2012 to 2014 (MAC www.happycity.go.kr). Although Lee administration has reluctantly pledged to remain on the current path, a series of drastic government restructuring took place and, inevitably, the total number of ministries and government agencies, including those relocating public officials, has been drastically reduced. That may also be the case in the relocation of public corporations to non-Capital Regions as elaborated later. Discussions began for overhauling and reshuf- fling the organizations of current public corporations, a majority of which are scheduled to move out of Seoul area.

"Enterprise Cities" were planned in order to permit firms to take an initiative in developing the countryside, thereby granting considerable incentives for firms. The main intent of building Enterprise Cities was to steer more active economic development in combination with residential and commercial development, thereby maximizing the vitality of the private sector. However, it remains doubtful whether the designation of Enterprise Cities mirrors the industrial and economic potential of each region (Lee 2007).

This program was unprecedented because the private businesses, even world-famous Korean conglomerates, Chaebol, had remained either targets or beneficiaries of government regulation or leadership, not the main players in this nature of land development. However, the relevant law entitled firms to make the first move and have access to a clearly faster permit process in addition to various regulatory waivers within designated areas. National and local governments even pledged to provide financial assistance and tax relief in order to encourage private investment, once it was designated.

Since the enactment of the Special Act on the Development of Enterprise Cities in 2004, six cities including Chungju, Muan, Taean, and Wonju, have initially been selected as target areas for the initial program of Enterprise Cities. The actual construction began in Taean in October 2007, which was followed by Chungju and Wonju. Even with apparently unfair preferential treatment for conglomerates, such as Samsung and Hyundai, in terms of development in these areas, the mid- and long-term performance of this project is still uncertain. While no clear sign of success or initial enthusiasm has appeared or been maintained in light of the development process or estimate on tangible achievement, certain negative signals are often exposed. The process has been very slow; the outcome has yet to become clearer. On the other hand, there is continuing criticism against little or no financial support from the government for this project.

Eleven Regional Innovation Cities (Innocities) that are to host a number of public corporations relocated from Seoul and its vicinity are noteworthy. This nature of large scale deconcentration project has never been attempted in the modern history of Korea. Creating an Inno-city, a 'share out' for every region, was a perfect showcase of the de-concentration campaign of the previous administration; major national public bodies, albeit not government ministries, were scheduled to be scattered around the nation, their numbers amounted to 175 from among a total of 345 state-owned bodies. 
Although every metropolitan city and province was 'distributed' seemingly fair number of moving entities, ${ }^{1}$ the competition within each region was nothing but tough. The strenuous political battle to become an Inno-city within each region was extended into another lower-level dispute among cities or counties. The repercussion from the process does not appear to have been fully addressed.

Overall, the Inno-city project appears to be relatively promising. Thus far, this project has survived various political obstacles. Since the official plan for relocating 28 agencies in the first round was settled and approved in December 2007, right before the former president Roh stepped down, 137 agencies out of 147 (the latest approval being nine organizations in May 2010) have finalized and got approved their relocation to each Innocity throughout the nation (http://innocity.mltm.go.kr).

With that said, however, the relocation of public agencies too faces a number of barriers, e.g., huge costs, reluctance of the employees of the agencies who are living in Seoul area, and, above all, opposition from the new ruling party. Despite the advantages and disadvantages associated with this project, it is still difficult to precisely evaluate the effectiveness of this project. Certain new ruling group members continue to argue that the concept of relocation is unreasonable and unrealistic. Not surprisingly, despite its survival thus far, all the Innocities projects around the nation have not been displaying any sign of speedy development, particularly since the current President Lee was sworn in in February 2008 and another one in the general election (for National Assembly) in April 2008.

As of January 2012, the project is well behind the schedule. According to the existing plan, major public organizations and their 32,000 employees were supposed to relocate from Seoul and the Capital Region by 2012, which has yet to happen. In fact, there is no agency or organization that has actually relocated in to any Innocities, although the compensation for the private properties in the Inncities has reached to $98.6 \%$ and selling in lots $64.4 \%$ on average(http://innocity.mltm.go.kr).

\subsection{National initiatives for cluster development}

National de-concentration campaign aside, a much earlier version of 'cluster development' outside the Capital Region would be science parks or technology parks in Korea -- the issue of which is neither new nor fully addressed in academia and practice. The continuing prototype scheme for Korea's science park is undoubtedly the development of the Daedeok R\&D Special District (Daedeok Innopolis) since early 1970s at a cost of approximately $\$ 30$ billion for the past 35 years. The unique place, the core of which is more popularly known as Daedeok Science Town, is located in Daejeon, the fifth largest city of the nation next to Daegu, and home to more than 70 prominent research institutes and hundreds of firms.

A number of smaller versions of the science town have been emulated since the late 1980s. For example, there are six techno-parks in different parts of the nation that were established with partial support of the central government since 1997 that are worth noting. ${ }^{2}$ In administrative terms, they are treated simply as national or local "industrial estates," however, they were expected to function as incubators to cultivate venture companies, conduct joint research and development for high-tech industries, and play a significant role as education and training centers. For example, the Gyeongbuk Techno-park in Gyeongsan near Daegu was established in an area of 36.8 acres at a cost of $\$ 67.5$ million. A mixture of entities has been involved in its establishment and operation: two local governments (Gyeongsan City and Gyeongbuk Province), five local universities, a local chamber of commerce and industry, and numerous private firms. The success of the establishment of this techno-park is uncertain, there have been signs that a large number of techno-parks are struggling and have not been successful in attracting high-tech tenants. It is believed that increased efforts and policy measures are necessary (Koo 2003; Lee 2003).

Apparently, the previous administration had attempted to create industrial and innovative clusters as part of its balanced development strategy. The creation of various types of clusters or other geographical agglomerations has been attempted recently. From an official viewpoint, each and every city, county, and province in the entire country is said to have been named "innovative cluster," and the Regional Innovation Committee, a powerful organizations under direct control of Presidential Office during the Roh administration, was established in order to participate in

\footnotetext{
1 The only exception outside the Capital Region was Daejeon, which was not invited in the relocation because the city of 1.5 million residents is already home to the Third Government Complex and the Daedeok Science Town.

2 Although the two terms, techno-park and technopolis, are used interchangeably in literature, these six techno-parks are considered much smaller than a technopolis, e.g., the Daegu Technopolis mentioned later in this paper.
} 
important decision-making process and resource allocation procedures. "Innovation" was a national mantra; "cluster" became a cliché not only in the planning profession but even in everyday conversation.

A majority of the government-funded projects entailed tough competition among localities as well as provision of sufficient funds by participating local authorities. The assignment of funds to a variety of small and large projects did not turn out necessarily equal because the foremost intention of the scheme was to utilize the potential of the localities' rather than fairly distribute resources, unlike the case of Inno-cities. Nevertheless, the rags to riches story was borne in mind to a large extent by the localities involved or those that were encouraged to apply; these attempts were promoted more broadly on a regional scale, e.g., at the level of provincial government.

\subsection{Small-scale special districts around the nation}

On top of large-scale development and clustering projects, there are a number of small "special districts"(SD) that must be discussed. Basically, the key purpose of these programs was to maximize local potential by developing, in a majority of the cases, historical assets, natural resources, or human factors. Understandably, all these SDs have been initiated by the national government, i.e., through the former Ministry of Finance and Economy and the former Ministry of Government and Home Affairs. Upon request for proposal by the ministries, each city or county was entitled to identify and make suggestions on detailed project plans along with financial needs and requirements.

$\mathrm{SD}$, teuk-gu in Korean, may be called a hybrid when it comes to their launch and operation. They have been influenced largely by national campaign but pictured and carried out by local or regional force. Since the system of special districts was introduced in late 2004 , local governments have been encouraged to join and benefit in order to get their industries or other features with comparative advantage promoted even further. There are no direct subsidies or tax reliefs from the national government but a number of regulatory exceptions may be granted. Until 2010, 410 regulatory exceptions out of 607 available have been granted. Additionally, in many cases, indirect financial support from the national or regional government has been provided as well.

In the beginning stage, the majority of the SDs focused on the development of local natural resources (e.g. medicinal herb, grape, strawberry), the trend has shifted greatly for the past seven years or so to high-tech industries (e.g. shipbuilding, solar energy), education (e.g. foreign language, international education), and so forth.

As an example of centralized de-concentration campaign, one can easily find out some distinctive features of SD development for the past seven years. First, a majority of the clustering projects, although aimed at de-concentration, have been initiated and implemented in a centralized manner by the national government, mostly by the Ministry of Knowledge Economy. That said, these "special" districts may

Table 2. Samples of special districts by region in Korea

\begin{tabular}{|c|c|}
\hline Region & Special districts (city's or county's name bold) \\
\hline Seoul City (5) & Dongdaemun Oriental Medicine SD; Nowon International Education SD; Jung-gu English Education SD \\
\hline Busan City (4) & Gijang Seaweed SD; Dong-gu China Town SD; Haeundae Convention/Film/Sea leisure SD \\
\hline Daegu City (3) & Buk-gu Glasses SD; Jung-gu Fashion Jewerly SD; Oriental Medicine SD \\
\hline Incheon City (3) & Ganghwa Medicinal Wormwood SD; Seo-gu Foreign Language Education SD; Jung-gu Chinatown SD \\
\hline $\begin{array}{l}\text { Gyeonggi } \\
\text { Province (10) }\end{array}$ & $\begin{array}{l}\text { Goyang Flower Industry SD; Gunpo Youth Education SD; Yeoncheon Experience Peace SD; Yangpyeong Eco-friendly Agriculture SD; } \\
\text { Yeoju Rice Industry SD; Icheon Ceramics SD }\end{array}$ \\
\hline $\begin{array}{l}\text { Gyeongbuk } \\
\text { Province (24) }\end{array}$ & $\begin{array}{l}\text { Gyeongsan Seedling Industry SD; Gimcheon Grape Industry SD \& Plum Industry SD; Mungyeong Omija Industry SD; } \\
\text { Bonghwa Pinetopia SD; Pohang Guryong Gwamegi SD; Sangju Dried Persimon SD; Seongju Melon Industry SD; } \\
\text { Cheongdo Persimmon SD; Andong Ma SD; Yeongdeok Clean Energy SD, Crab SD; Uiseong Garlic Industry SD; } \\
\text { Yeongyang Experience Eco-village SD; Yeongju Global HR Education SD }\end{array}$ \\
\hline $\begin{array}{l}\text { Jeonbuk } \\
\text { Province (14) }\end{array}$ & $\begin{array}{l}\text { Gochang: Scenery Farming SD \& Mountainberry SD; Gimje Beef Industry SD; Namwon Wellness Herb SD; } \\
\text { Buan Film SD, Silkworm SD \& New Recycling Energy SD; Sunchang Paste Industry SD; Wanju Women Herb Clinic SD; } \\
\text { Iksan Oriental/Western Medicine SD; Jinan Red Ginseng Medicine SD }\end{array}$ \\
\hline $\begin{array}{l}\text { Jeonnam } \\
\text { Province (29) }\end{array}$ & $\begin{array}{l}\text { Gangjin Foreign Language SD; Gokseong 21C Advanced Education SD; Boseong Herb Tea SD; Suncheon International Education SD; } \\
\text { Yeosu Osean Resort SD, International Tourism SD \& City Park Resort SD; Jangheung Oriental Medicine SD; Hanpyeong Butterfly SD }\end{array}$ \\
\hline
\end{tabular}


not be special any more, largely because they are present just everywhere throughout the nation. Every inland province has at least 10 (in Gangwon and Gyeonggi), and as many as 29 (in Jeonnam), SDs; metropolitan cities also are home to two (in Ulsan and Gwangju) to five (in Seoul) SDs. As of December 2011, the number of SDs in the nation has reached to 150 of which just a few examples are presented in [Table 2] (MKE 2011).

[Table 3] indicates major types by which the money has been allocated; there certainly is some variation. For instance, medical and health field has not attracted sufficient investment as initially planned, while such categories as education, industries \& research, and local resources have been finance-wise so successful. It may be time for setting priorities and making tough choices.

Third, a large number of these projects, similar to the case of techno-parks, have not fully developed the endogenous potential or vitality of the private sector of each area. Based on ministry-initiated requests for proposals, a number of fartoo-compliant local governments made haste in developing a plan within limited resources merely to meet the deadline. Multiple localities, urban and countryside alike, have been designated, and share the name of, improbable "international" or "foreign language" education SDs in such areas as Asan, Gangjin, Geochang and Changnyeong, most of which are considered rural areas or farming communities. In certain cases, one city or county has been designated multiple SDs as partly shown in [Table 2]. It has been suggested that overlapped designation simply hinders efficient or concentrated support and development by already financially-struggling localities.

Last issue has something do with overall capacity and effectiveness. It appears that numerous local governments simply cannot afford the project in terms of the local capacity

Table 3. Investment distribution in special districts ( $W$ billion, \%)

\begin{tabular}{|c|c|c|c|c|c|c|}
\hline \multirow[b]{2}{*}{ ( $W$ billion) } & \multicolumn{3}{|c|}{2010} & \multicolumn{3}{|c|}{$2004-2010$} \\
\hline & planned & invested & (\%) & planned & invested & $(\%)$ \\
\hline medical, health & 139 & 3 & 2.4 & 348 & 51 & 14.9 \\
\hline tourism, leisure & 687 & 262 & 37.5 & 2,179 & 1,552 & 71.3 \\
\hline education & 154 & 172 & 111.5 & 411 & 452 & 110.0 \\
\hline logistics & 135 & 105 & 77.7 & 467 & 456 & 97.6 \\
\hline industries, research & 383 & 290 & 75.8 & 1,643 & 1,638 & 99.7 \\
\hline local resources & 387 & 454 & 117.4 & 1,267 & 1,509 & 119.1 \\
\hline (Total) & 1,888 & 1,288 & 68.3 & 6,317 & 5,661 & 89.6 \\
\hline
\end{tabular}

despite having been awarded the designation of an SD. In certain cases, no further action has been taken since the official designation, with the exception of some procedural measures. Apart from insufficient grants-in-aid from the national government, it is argued that certain local governments, particularly the elementary-level counties rather than autonomous districts in metropolitan cities, have yet to develop - in addition to taking much more time -- their capacity and experiences to undertake such tasks.

The effectiveness of the SDs has yet to be proved not only in terms of expectation but also in the actual course of action. Although it may be early to comprehensively evaluate the programs, it is argued that a majority of the SD projects have already been stalled or lost their momentum. This has happened mainly due to poorly initiated plans, lack of financial resources, lukewarm contribution from the private sector, and above all, lack of the overall capacity to continue.

Criticism against the development of numerous SDs in the past years may have been politically motivated because of the implication of the motive of balanced development. There appears to be simply large variation in terms of the progress of an SD and what it has already accomplished. A systematic and comprehensive analysis in this regard should follow.

\section{REGIONALLY CONCENTRATED EFFORTS FOR CLUSTERING}

As discussed, the overall de-concentration projects appear to have slackened or faced challenges. In all fairness, the initial efforts of the previous administration deserve appreciation; they have yet to prove feasible and accomplish much more in the future. The current administration which opposes, in principle, calculated government intervention or continuing the de-concentration drive may in fact damage the overall process in the future. In this context, regional efforts for cluster development find its place.

\subsection{National competition for de-concentration projects}

Particularly from the beginning of the 21st century, there have been fierce competition in Korea among regional/local governments for attracting 'nationally distributed' clusters and projects; encouraged competitions often resulted in negative backlashes in many cases. Local governments have competed intensely for clusters to be located in their jurisdictions. Since the direct costs of such competition were most frequently exhaustive paper work and 
pledges for requisite funds from local governments, it is not surprising that concerted efforts to convince national governments to create clusters or SDs have been witnessed over the past few years. The potential incentives for the competitions were, in a majority of the cases, grants-in-aid and regulatory waivers from the national government and other related resources provided along with the projects. The seemingly fair competition has not always yielded fair results, let alone effective ones.

Major criticism against this course of action has something to do with the validity and consistency of the criteria on which final decisions were made. A few years ago, large cities like Daegu and Daejeon, both in the non-Capital Region, lost in national competition for huge projects such as the Magnetic Levitation Train project and Robot Land development, and have joined in fierce condemnation against the central government on account of spatial inequality (Incheon, another metropolitan city adjacent to Seoul, won both projects).

The massive government-initiated project High-tech Medical Complex, for which relevant laws have already been enacted and approximately $\$ 5.8$ billion - or $\mathbb{W} 5,600$ billion -- will be invested in the next 30 years, was another national large-scale project. After fierce competition among 10 cities, including major ones such as Daejeon, Incheon, and Pohang, Daegu won the big prize; For Daegu, gaining the complex was a rare political victory as well as an economic assurance.

Undoubtedly, none of the national balanced development projects planned during the Roh Administration are welcomed now and that most have been significantly changed in its nature and scale by the current administration. This is largely because the various proposals of the Lee administration on economy and spatial development are premised on the view that market in partnership with firms is the primary force for becoming an "advanced country" and that balanced development excluding the Capital Region is inefficient as wells as unfeasible. In this world, competition in market mechanism is far more encouraged and promoted just as in textbook; concentration, not de-concentration, is considered economically efficient and even socially more desirable. Accordingly, local governments are urged and even forced to make every effort to facilitate the creation of clusters in their jurisdictions, even without external help or initiation.

\subsection{Daegu case: Technopolis and more}

The way clusters of various types have been created in Korea's regional context, particularly over the past years, is quite different from national one. Great attention should be on endogenous efforts, region-wide cooperation, and 'concentrated' development within a region with potential in terms of technology, education, culture, etc. Daegu, the fourth largest metropolitan city in Korea, has not only participated in the national competition for clusters, but also pursued creating its own clusters.

\section{Daegu and its assets}

Daegu, located inland and southeast on the Korean peninsula, boasts ample historic and cultural assets within and adjacent to the city. The region has also been home to a number of distinguished people in such fields as politics, economy, and culture. However, recent decades have witnessed the downgrade of the city from the top regional center of Korea to a mere declining local city. Daegu is certainly not an isolated case in the discussion of issues such as downtown deterioration, sluggish economy, decreasing jobs, and environmental degradation. While Korea has enjoyed a series of assorted benefits from its world-renowned rapid economic growth over decades, Daegu region appears to remain one of the least benefited, or even the most steadilyhit by the recent economic stalemate.

The city of Daegu, the birthplace of Samsung, encompasses an area of approximately $885 \mathrm{~km}^{2}$, or $0.9 \%$ of the total land of the nation. The number of residents is approximately 2.5 million, which is $5.3 \%$ of Korea's total population of about 48 million. Daegu Metropolitan City is one of the seven regional governments in Korea.

The typical regional city of Korea has had its defining moments and appears to remain proud of its abundant resources. Daegu is often been labeled 'the city of scholars.' What the citizens are still proud of is that, as an old saying goes, approximately half of the prominent scholars and highlevel officials of the nation are said to have been from the Youngnam -- of which the city has been the political hub for more than 400 years, since the 17 th century. Daegu has recently hosted several international events such as a portion of the 2002 FIFA World Cup and the entire events of the 2003 Summer Universidad and the IAAF World Championship in Athletics in 2011 [summarized from (Lee and Park 2008)].

\section{Efforts for clustering in Daegu}

As mentioned earlier, a majority of the recent cluster development cases in Korea have been driven by the national government, and it is not easy to identify practices based entirely on local initiation. This is also partially because Korean localities have continuously benchmarked each other. Daegu, 
which has suffered from a great deal of economic difficulties in past decades, has also begun cluster development, thereby attempting to create another economic base on its own while competing for the nationwide cluster 'war.'

To begin with, Daegu will be the new home for 12 public agencies, including the Korea Gas Corporation, which is scheduled to relocate from the Capital Region, as discussed earlier. Daegu is just one of the beneficiaries of the legacy of the nationwide balanced development campaign, although the actual effectiveness of the repositioning work is anything but certain. With the abundant human resources in the region, e.g., approximately 50,000 annual graduates from over 30 colleges and universities, Daegu City has taken initiative in developing more specified knowledge-based, and yet business- and education-oriented, projects in its Innocity. Although Daegu is another land-hungry city in Korea, a significant portion of land within the boundaries of the city had been saved for the site of the Innocity, or Palgong Innovalley, for public agencies that are relocating from Seoul region.

The economic reality of Daegu requires something far more than usual. For a start, its GRDP per capita is the lowest among all metropolitan cities and provinces in the nation. In the manufacturing industry, which accounts for $21.7 \%$ of the GRDP of Daegu, has been declining constantly for decades. Admittedly, the leadership of the local government in restructuring the city's old-fashioned industry was not as successful as intended. Textile and other labor-intensive production continuing to be the major industry in Daegu, knowledge-based industry accounts for much less than $50 \%$ of Seoul, and is even smaller than the national average. Daegu has attracted the lowest level of foreign direct investment (FDI) in the nation for the past four decades. Deteriorating industrial complexes and declining productivity have caused sufficient trouble. Since the 1980s, huge projects such as the construction of the Wicheon Industrial Park and the Bongmu Apparel Complex have been attempted, only to fail. The effectiveness of the "Milan Project" in the 1990s to support and regenerate local textile industries continues to be disputed (Lee and Park 2008). ${ }^{3}$

Reviewing the existing conditions for industrial clusters in Daegu, Park et al. (2003) too suggested that the industrial clusters have not yet been well developed in the city. Clustering depended, understandably, on each industry; however, at the time of analysis, the levels of major components, such as localization, embededness, and institutionalization of industries, appeared about average, while competitiveness in general was slightly below average, the study found.

In addition to the specific and detailed analysis of individual industry as in Park et al. (2003), several on-going largescale projects can be marked: the Culture Industry Cluster, the Daegu Technopolis, and, more recently, the Brain City project. The first major project, a culture industry cluster, isconsidered one of the most promising alternative policy means for regional development. Daegu is not the only city that is developing a culture industry cluster since the mid1990s; it is one of the few local cultural industrial districts designated and supported by the national government since early 2000's. Yet the role of City Hall has been rather clear and meaningful.

Emphasizing the IT resources and abundant cultural assets of the city, the Daegu Culture Industry Development Master Plan was developed and authorized in 2004, and a redeveloped college site in the city center was selected for constructing theme parks, traditional folk villages, and various exhibition and convention facilities. The initial phase is expected to be completed by 2015, with an estimated cost of $\$ 1.4$ billion, a similar cost for building Burj Khalifa, a 160-story 828-meter tower in Dubai, UAE. In 2008, the former college site of 120 thousand square meters in the downtown area has been officially designated by the Ministry of Culture and Tourism as the Culture Industry Promotion District, together with seven other cities (Youngnam-ilbo 2008. 2. 29). ${ }^{4}$ Significant tax benefits and partial financial support are provided to firms and entities in these districts.

The second is the decade-old Daegu Technopolis project. If a technopolis is "an agglomeration of highly innovative activities structured as a network in which the emergence of cooperative ties among the scientific, technical, educational, and institutional agent is expected to enhance the technological and innovative capability" (Chorda 1996 - requoted from Koo 2003) for overall competitiveness, that is exactly what the city government intends to achieve through the

\footnotetext{
3 The Milan Project was named after a namesake Italian sister city of Daegu, referring to the hope and efforts of the city to revitalize the century-long textile industry of Daegu into a high-tech business and contemporary design and fashion industry.

4 The Daegu cultural industrial district is specialized in game industry and mobile contents. The other cities are Bucheon (publishing, animation), Cheonan (cultural design), Daejeon (film, game), Gwangju (character), Jeju (digital film, mobile contents), and Jeonju (Film) (Choo 2007).
} 
project. The site for the Daegu Technopolis, located southwest of the city and encompassing an area of 1,800 acres, is intended to be a future center for research, industry, education, and housing.

Although the initial plan was already prepared in the late 1990s, the actual construction began only in 2006 in partnership with the Korea Land Corporation; it is scheduled to be completed by 2015 , at a cost of approximately $\$ 2$ billion, or W 1,900 billion. While hosting leading-edge manufacturing industries and residential development, it would be home to some major research institutes such as the DaeguGyeongbuk Institute of Science \& Technology (DGIST), an ETRI branch, the National Science Center, and possibly the KNU College of Engineering and the Medical School (Lee and Park 2008). In particular, DGIST has officially been launched in November 2010 after two year construction; the first cohort of master and doctoral students was matriculated in March 2011 (DGIST 2012).

This significant project has not greatly benefited thus far from any systematic and stable support from the national government. (one of the convenient justifications, especially before 2008, would be that the entire region had been far away from the political inner circle for the "10 lost years.") As the name DGIST suggests, the whole project is in a large sense a momentous outcome of institutional cooperation between Daegu Metropolitan City and Gyeongbuk Province. How the project will turn out remains to be seen. A greater issue will be the number of quality firms and research entities the city and the neighboring Gyeongbuk Province can attract in the coming years.

\section{Regional FEZ}

A notable goal that the City of Daegu in partnership with the neighboring Gyeongbuk Province is to create a successful Free Economic Zone (FEZ) within the region. The establishment of an FEZ had been encouraged since 2007, mostly by local leadership, so as to offer "optimal business environment by providing financial incentives, relaxed regulations, and customized facilities to global companies" (DGFEZ 2012). DGFEZ covers a total area of $40 \mathrm{~km}^{2}$ in 10 separate industrial districts in Daegu and four cities (Gumi, Gyeongsan, Yeongcheon and Pohang) of Gyeongbuk. This is one of the latest FEZs in Korea approved in 2008.

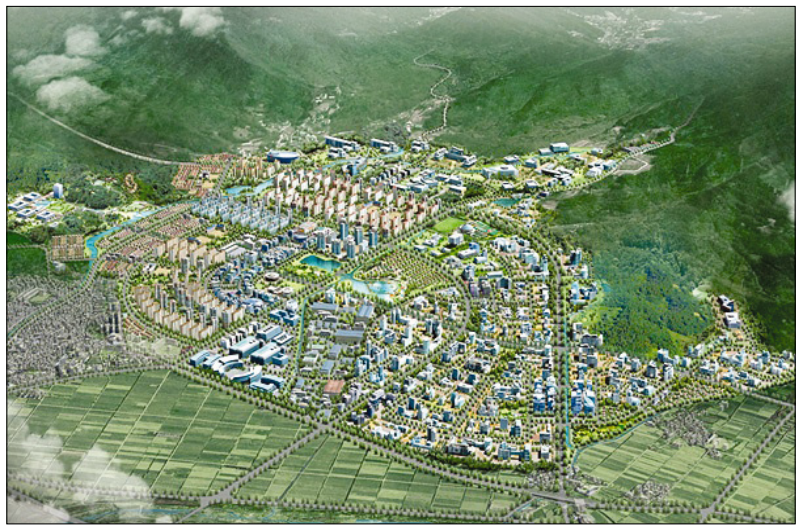

Fig. 1. A blueprint for Daegu Technopolis within Daegu Gyeongbuk FEZ Source: DGFEZ (2012).

Although, the whole project is within national government's 'Big Picture,' DGFEZ has been administered by the Daegu Gyeongbuk Free Economic Zone Authority, which is a special local government organization, or local government in operation union. The Authority is almost entirely staffed and financed by Daegu Metropolitan City, Gyeongbuk Province, and other four cities. In fact, it was local community as a whole that identified the necessity and justification of DEFEZ in the first place. Scholars, the press, politicians, non-governmental organizations and City Hall have reportedly shown unusual cooperation in the process. Of course, the role and influence of Seoul, mostly through the Ministry of Knowledge Economy, are still sensed when it comes to major institutional changes and financial assistance.

Although it is not as large as the FEZs in Dubai (JAFZ, $\left.100 \mathrm{~km}^{2}\right)$, UAE, or Incheon $\left(209 \mathrm{~km}^{2}\right)$, DGFEZ is a promising start. That said, it has a long way to go; no meaningful FDI has been attracted so far. The city in tandem with the partner province and cities pursues the progress of knowledgebased service and manufacturing industries simultaneously. Again, tangible inducements, including exemption or significant reduction of land-leasing costs, tax holidays and relief, cash grants, support for urban infrastructure, are to be provided, in addition to regular incentives for FDI, for the firms, businesses and educational entities within the DGFEZ. ${ }^{5}$

Overall, the current efforts of Daegu to restructure the entire industry are centered on a few grand projects for the provision of research and industrial space, rather than on

\footnotetext{
5 The Daegu cultural industrial district is specialized in game industry and mobile contents. The other cities are Bucheon (publishing, animation), Cheonan (cultural design), Daejeon (film, game), Gwangju (character), Jeju (digital film, mobile contents), and Jeonju (Film) (Choo 2007).
} 
scores of small-scale clustering projects. As introduced, the first promising clustering project, Daegu culture industry cluster, is relatively central government-oriented. Daegu City successfully attempted to gain the project and survived fierce competition; the project has been launched, along with administrative and financial support from both national and local governments.

The other two schemes, the Technopolis and the DGFEZ, can be regarded as comparatively more endogenous in that the local government identified locally unique and abundant assets and began focusing on development of the resources. Yet Daegu City was not, and will not be, entirely independent for all these projects; the city has recently expected varied aid help from the national government, partially for the reason that the current president and his inner circle members are rooted in this region. To a large extent, it is believed that indeed happened for recent years.

One other feature in recent times is that region-wide cooperation has been unusually emphasized, particularly since 2006. Daegu Metropolitan City and its parent Gyeongbuk Province, which have occasionally focused on competition rather than on cooperation or built an antagonistic relationship with each other, have lately displayed genuine cooperation. ${ }^{6}$ Furthermore, the so-called "ultra regional' cooperation has been suggested, implying collaboration with the Busan and Gyeongnam region. As a beginning, substantial measures that must be taken seriously would include the expansion of region-wide infrastructure, such as regional international airport and additional expressways.

Based on a recent agreement between Daegu City and Gyeongbuk Province on economic integration in 2007, some promising projects identified and agreed upon by both are already in practice or under serious consideration, e.g., in the nationwide competition for High-tech Medical Complex as previously mentioned. In fact, region-wide cooperation has particularly been underscored since the launch of the new administration in February 2008, as indicated in a grandiose plan to restructure the entire nation with five large economic zones and two special large economic zones (so called " $5+2$ " blueprint). It is an apparently new and different version of the nationwide economic development plan from the 'national balanced development strategy' of the Roh administration. Daegu region also faces opportunities as well as challenges.

\section{CONCLUSION}

This article examined the overall pattern of cluster planning and regional development in Korea over the past decade or so. Academic literature aside, the relevant information and data used for this paper, drawn mostly from official sources, appear to be reliable and could be reinforced by further examining actual cases in other geographical settings. Using a meta-analytic approach, I attempted to identify two distinct patterns of cluster development: centralized deconcentration and regionalized concentration.

Apparently, the majority of notable clusters in this country have seldom grown through market mechanism. National and local governments have taken initiative in launching and implementing clustering campaign; regional efforts have been made with limited success. Instead of arguing an issue or suggesting a theory in detail, this article focused on observing the recent experiences of the nation and Daegu as an example in the context of cluster or regional development.

It has now become conventional wisdom that creating clusters is a promising method for nurturing entrepreneurship, thereby turning it into an alternative policy means for regional development. Yet, the overall process and its effectiveness are not very easy or clear in Korea. Admittedly, nationally driven efforts have usually dominated and fared well, as was the case with Korea's rapid economic growth in general. However, for the past decade or so, numerous large-scale centralized projects have stalled, been delayed or implemented with far less enthusiasm. In this context, regional attempts seem to have come into play with mixed results, limited early success and on-going challenges as well, as implied in Daegu case.

From the localities' viewpoints in Korea, the recent development pattern of clustering, particularly in the wider context of national de-concentration, was largely worth noting without regard to its actual success or failure. In that sense, a number of locally-favored clustering efforts present both advantages and great challenges that must be overcome.

\footnotetext{
${ }^{6}$ Daegu was administratively under the jurisdiction of Gyeongbuk Province until 1981, when Daegu was promoted to a metropolitan city. The city has been separated since then, not only administratively but also economically in a large sense, from Gyeongbuk Province.
} 
Centrally-designed and -implemented development may have sufficiently displayed its limitations; local/regional governments stand at a crossroad with regard to where they can choose to initiate and proceed on their own paths, quite possibly without much support from Seoul.

For instance, Daegu, still struggling despite its great assets, must also address similar questions: how cluster development can be translated into actual progress; and who should take part in clustering with what means. The advantages of clustering in the time of knowledge-based society do not have to be suspicious; of importance is a distinct differentiation from other similar measures for regional development on almost all grounds, including its governance. The real work remains unattended, with different paths still ill-explored.

\section{REFERENCES}

Choo, S. (2007) "Cultural Industrial Districts as a Tool of Boosting Regional Economy in Korea," Journal of the Economic Geographical Society of Korea 10(3): 332-43.

Chorda, I. M. (1996) "Towards the Maturity Stage: An Insight into the Performance of French Technopolis," Techno vation 16(3): 143-52. [re-quoted from Koo (2003)]

"Science \& Technology," Daegu Gyeongbuk Institute of Science and Technology. accessed, March 2012. available online http:// www.dgist.ac.kr.

"Knowledge Creation," Daegu Gyeongbuk Free Economy Zone. accessed, March 2012. available online http:// www.dgfez.go.kr.

Feldman, M., and Francis, J. L. (2006) "Entrepreneurs as agents in the formation of industrial clusters," in Cumbers, A., and MacKinnon, D.(eds), Clusters in Urban and Regional Development (London: Routledge).

"Innocity," Ministry of Land, Transport and Maritime Affairs, Republic of Korea. http://innocity.mltm.go.kr/public/ public03.jsp. accessed, March 2012.

Koo, C. (2003) "An Analysis and Suggestions for Korean Technopolis Toward Mature Development Stage," Journal of Korea Planning Association 38(1): 213-35.

Lee, S-C. (2007a) "Recent Decentralization Challenges in Korea," International Review of Public Administr ation 11(2): 15-27.

Lee, S-C., and Park, S-G. (2008) "Spatial Regeneration and Beyond: Daegu, Korea," in Kidokoro, T., et al.(eds.),
Sustainable City Regions: Space, Place and Governance (Tokyo: Springer), 101-25.

Lee, S-G. (2003) "Cooperative Regional Development for Technological Innovation: A Case Study of the Kyongbuk Technopark," Asian Pacific Planning Review 2(1): 1-13.

Maskell, P., and Lorenzen, M.(2006) "The Cluster as Market Organisation," in Cumbers, A., and MacKinnon, D.(eds) Clusters in Urban and Regional Development (London: Routledge).

Organisation for Economic Cooperation and Development. (2002) International Conference on Territorial Development: Local Clusters, Restructuring Territories, and Environment-Enterprises-Districts. (Paris: OECD - DATAR).

Ministry of Knowledge Economy. Republic of Korea (2011) 2011 Annual Report on Local Special Districts. (Seoul: Ministry of Knowledge Economy. Republic of Korea.).

"SEJONG : A Multifunctional Administrative City," Multifunctional Administrative City Construction Agency. available online http://www. happycity.go.kr. March 2012.

Park, J-H. (2004) "Issues in Industrial Cluster,"(in Korean) Korea Policy Studies 4(1): 57-76.

Park, J-H., et al. (2003) Substances and Development Measures of Industrial Clusters in Daegu Metropolitan Area: A research report for the Ministry of Science \& Technology and Daegu Metropolitan City (Seoul, Republic of Korea: Ministry of Science ; Technology and Daegu Metropolitan City).

Porter, M. E. (1990) The Competitive Advantage of Nations (Basingstoke: Macmillan).

Porter, M. E. (1998) "Clusters and the New Economics of Competition," Harvard Business Review 11(NovDec): 77-91.

Porter, M. E. (2000) "Location, Competition and Economic Development: Local Clusters in a Global Economy," Economic Development Quarterly 14(1): 15-34.

Richardson, G. B. (2000) "The organization of industry," Economic Journal 82: 883-96 [requoted from Maskell and Lorenzen].

The City of Daegu. (2008) Daegu-Gyeongbuk Free Economic Zone.

"The former Kyemyeong University site designated as Culture Industry Promotion District," (in Korean) Youngnamilbo (Daegu, Republic of Korea). February 29, 2008. 